\title{
UTOPIA: DO IMPOSSÍVEL COMO POLÍTICO ${ }^{1}$
}

\author{
Silvio Ricardo Gomes Carneiro ${ }^{2}$
}

Resumo: O artigo é uma análise do caráter histórico de utopia. Para tanto, articula as reflexões de Souza e Finley sobre as utopias clássicas e desdobra a contemporaneidade do conceito pela perspectiva de Marcuse sobre o "fim da utopia". Nesse sentido, o artigo opera o pensamento utópico enquanto crítica da Modernidade.

Palavras-chave: Utopia - Historicidade - Teoria Crítica - Modernidade

A map of the world that does not include Utopia is not worth even glancing at,
for it leaves out the one country at which Humanity is always landing. And
when Humanity lands there, it looks out, and, seeing a better country, sets sail.
Progress is the realization of utopias.
Oscar Wilde

Em primeiro lugar, este texto leva em consideração um curso dado pela profa. Maria das Graças, que assisti como ouvinte, a respeito dos modelos de utopias. Decerto, grande parte deste curso pode ser encontrado no artigo "O real e seu avesso: as utopias clássicas". 3 Sobre esse curso, ressalto a marca de sua diferença. Pois tratava-se de um estudo rigoroso de história das ideias, ou mesmo um percurso sobre a história da filosofia que um relato utópico carrega consigo. Um material diverso, portanto, que traz novas luzes aos modos como a crítica da modernidade pode ser conduzida.

É interessante notar, pois, como - às portas da Modernidade - as utopias surgem como modelos críticos fundamentais para escapar dos sistemas de racionalidade representativos da Modernidade; ou melhor dizendo, pois não se trata aqui de afirmar a utopia como um modelo de crítica da modernidade pela mera irracionalidade dos desejos impossíveis, tal experiência do pensamento utópico carrega consigo novas formas de

\footnotetext{
1 Apresentado no Colóquio Nacional de Filosofia na História: “Tempo, História e Sociedade”, em homenagem à profa. Maria das Graças de Souza (maio de 2015).

2 Professor de Filosofia do CCNH/UFABC. Pesquisador do grupo Nexos Sudeste - Teoria Crítica e Pesquisa Empirica. E-mail: silviocarneiro@gmail.com

3 SOUZA, Maria das G. "O real e seu avesso: as utopias clássicas”, in Sexta-feira, pp. 11-22.
} 
racionalidade, talvez mais necessárias do que nunca se a questão final é como desenvolver uma crítica a Modernidade, que tem como princípio justamente a autocrítica contínua. ${ }^{4}$

Para tanto, falemos também de outro " $\mathrm{M}$ " a ser homenageado quando se trata de utopias. Pois, certamente, algum resíduo desse curso da profa. Maria das Graças alimenta meu interesse por autores que não dispensam a força crítica da utopia, como Herbert Marcuse. Lembro uma das provocações desse autor aos estudantes - grande parte formados nas diversas correntes do marxismo em 1968: "eu diria que nós estamos diante da possibilidade em que a tendência para o socialismo pode vir da ciência para a utopia (...) e não da utopia para a ciência”. ${ }^{5}$ Nessa provocação, Marcuse inverte os passos marxistas rumo ao socialismo científico. Recupera, pois, a tendência da utopia que, talvez, Marx e Engels tenham dispensado de maneira severa e um pouco cega diante da ideologia do progresso.

É preciso compreender tal mudança nos termos conforme Marcuse. Pois, com isso, em primeiro lugar, ele não deseja organizar estratégias no fórum político baseadas na fragilidade do devaneio fantástico. Em segundo lugar, o autor não se afasta do pensamento marxista, mas aprofunda algumas das suas tendências, como o elogio crítico a Fourier, o único - segundo Marx e Engels - capaz de organizar o trabalho necessário em harmonia com as necessidades genuínas dos homens.6 Força social que alimenta modelos sociais que atravessam o continente, com forte presença em muitas comunidades dos EUA. ${ }^{7}$ Portanto,

4 Autocrítica que compreendemos em termos muito próximos aos de Foucault em seu ensaio "O que são as Luzes?’”. Na análise da questão kantiana sobre o esclarecimento, Foucault não mede palavras para pensar os dois movimentos ali inaugurados. Por um lado, a noção epistemológica da constituição do conhecimento verdadeiro como possível, uma "analítica da verdade". Por outro, e este nos interessa mais, uma "ontologia do presente", apresentado por Foucault da seguinte maneira: "um pensamento crítico que tomará a forma de uma ontologia de nós mesmos, uma ontologia da atualidade. Foi essa filosofia que, de Hegel à Escola de Frankfurt, passando por Nietzsche e Max Weber, fundou um modo de reflexão no qual procurei trabalhar" (FOUCAULT, “O que são as luzes?” in FOUCAULT, Arte, Epistemologia, Filosofia e História da Medicina - Ditos e Escritos - vol. VII, p. 268).

5 MARCUSE, Das Ende der Utopie, p. 10.

6 MARCUSE, Das Ende der Utopie, p. 17.

7 Sem dispensar os problemas apresentados na arquitetura utópica de Fourier, notada pelo próprio Marcuse em Eros e civilização, no capítulo "A transformação da sexualidade em Eros" - um exemplo que lhe é caro, por ser suporte para uma nova ordem erótica. É bem verdade que toda a ordem de trabalho adotada nos falanstérios inspirados em Fourier, adotaria elementos que contrariam, de início, os vínculos agressivos do trabalho sobre a natureza externa, bem como alimenta novos princípios em que se efetivam a formação de grupos libidinais de amor e amizade, o estabelecimento de uma ordem harmônica, o desenvolvimento de grupos de trabalho conforme as "paixões" individuais - enfim, a possibilidade de realização dos desejos em uma nova ordem de trabalho, ou melhor, a dessublimação dos impulsos outrora alienados pelo chão de fábrica. No entanto, Marcuse não deixaria de notar problemas desta própria arquitetura, cuja planta ainda retém os elementos repressivos. Nesse ponto, o autor afirma que uma observação detalhada das plantas dos falanstérios, faz notar a liberação de potências através do gozo mais do que a liberdade propriamente. Neste espaço utópico reside aquilo que Marcuse interpreta como uma "organização gigante da administração", correndo todo o risco de tornar o jogo livre em um novo ciclo de alienação do trabalho submetida não mais ao proprietário, mas ao todo coletivo que se expressa sob a forma da administração (MARCUSE, Eros and civilization..., pp. 217-218). 
entender a crítica embutida nos discursos utópicos significa compreendê-los de antemão como estratégias que se dão no tecido social.

Em que medida isso é possível? Dúvida presente em Jürgen Habermas, que desloca o conteúdo utópico das estratégias críticas e, em defesa da Modernidade, reduz o esforço marcuseano a uma descrição romântica de certa "ressurreição da natureza caída". Tal crítica pode ser encontrada quando Habermas descreve a alternativa marcuseana de uma possível interação com a natureza da seguinte forma:

Em vez da natureza explorada, buscar a natureza fraternal. Na esfera de uma intersubjetividade ainda incompleta podemos presumir subjectividade nos animais, nas plantas e até nas pedras, e comunicar com a natureza em vez de nos limitarmos a trabalhá-la com rotura da comunicação. E, para dizer o mínimo que dizer se pode, essa ideia conservou um atractivo peculiar, a saber, que a subjectividade da natureza, ainda agrilhoada, não se poderá libertar antes de a comunicação dos homens entre si não estar livre da dominação. ${ }^{8}$

Habermas se refere aqui às decorrências da utopia marcuseana presentes nas imagens de Orfeu e Narciso, pelas quais a relação entre sujeito e objeto é preenchida pela linguagem erótica e pela expressão estética contrárias ao trabalho da dominação da natureza na imagem moderna de Prometeu. ${ }^{9}$

Decerto, há nessa crítica de Habermas um desvio curioso que retira do caráter utópico o seu potencial crítico. Algo que, em defesa das instituições modernas amparadas por uma crítica normativa que articula reformas internas no sistema de vida, produz interpretações equivocadas sobre a proposta marcuseana, encarada praticamente como uma revolução permanente de sujeitos românticos. ${ }^{10}$

Uma organização pouco diversa da sociedade unidimensional da libido administrada que descreve, alguns anos mais tarde; sobretudo, se considerarmos os novos modos de trabalho em sistemas pregados pela Google, que defende o tempo livre para a criação de produtos no interior de um modelo de metas produtivas.

8 HABERMAS, Ciência e técnica como "ideologia", p. 53.

9 Não desenvolveremos estes temas aqui, por ter como finalidade a compreensão do projeto utópico de Marcuse. Interessa-nos o fundo da questão proposta por Habermas, que deixa de escanteio o potencial crítico utópico diante dos sistemas ideológicos modernos. Para o tema dos mitos, indicamos MARCUSE, Eros and civilization..., capítulo “The images of Orpheus and Narcissus”, pp. 159-171.

10 Algo que encontramos na leitura parcial de Ricardo Terra sobre a questão da revolução em Marcuse. Na conclusão de seu artigo "Herbert Marcuse: os limites do paradigma da revolução: ciência, técnica e movimentos sociais", Terra acaba considerando a recepção brasileira de Marcuse acrítica quanto às possibilidades de certo, podemos dizer com Habermas, fascismo de esquerda, que retoma "o lado revolucionário de seu pensamento, não importando discutir sua efetividade" (TERRA, "Herbert Marcuse..." in NOBRE, M., Curso livre de teoria crítica, p. 156.). Sua crítica se pretende legítima a partir da crítica que Habermas dirige a Marcuse sobre os limites da racionalidade erótica no terreno da democracia. Não estaria Marcuse defendendo uma "ditadura da educação", 
Sem dúvida, o curso da profa. Maria das Graças continha uma crítica a essa compreensão habermasiana. Com "um passo atrás e dois à frente", a professora preparava com a análise das utopias clássicas o terreno que sorverá estas narrativas alguns séculos depois, com a crítica da modernidade revolucionária. Nesse sentido, reconhece na descrição das utopias seu contraste narrativo no alvorecer da Modernidade. Perceber tal contraste, pois, faz da utopia não apenas um não-lugar deslocado da realidade, mas um isolamento em que fervilha o juízo crítico do bem-viver bloqueado pelos processos de um horizonte revolucionário da sociedade moderna. Não se trata aqui de um discurso nostálgico de um passado perdido (como aparecia nos discursos presentes na Antiguidade sobre a Idade de Ouro da humanidade). A cidade isolada da utopia continha em grande medida as promessas da modernidade sem suas mazelas. Mais ainda, compreende Marcuse, haveria uma história contida na narrativa das utopias, uma temporalidade que é própria delas. De modo que, mesmo em sua forma "a-histórica" ou "trans-histórica", lembra Marcuse, a utopia deve ser concebida como um conceito histórico. ${ }^{11}$

\section{A utopia na ordem do tempo}

Em geral, associada às metáforas do espaço, a utopia no registro marcuseano é pensada de outra maneira, em seu caráter temporal. Assim, é central se questionar qual lugar a utopia ocupa na ordem do tempo? Na verdade, mesmo em seu caráter a-histórico, a apresentação da utopia é histórica uma vez que pressupõe na realidade efetiva os limites da sua efetivação. ${ }^{12}$ Isso porque seus elementos são um "avesso" da realidade social, conforme

nos moldes platônicos e rousseauístas, quando dispensa os ganhos de uma "unificação racional" para o corpo político da esfera pública democrática, recorrendo aos princípios de uma ditadura educacional em direção às revoluções culturais de uma nova sensibilidade? Para Terra, o próprio Marcuse reconheceria "mais tarde" (sem dizer onde nem quando) que esse termo não deve ser empregado. Há uma cortina de fumaça, pois a resposta é dada pelo próprio Marcuse logo em seguida e faltou ao intérprete um trabalho de reflexão a partir disso. Terra deixa de lado a resposta central de Marcuse a Habermas. Pois saber da convergência de uma "ditadura educacional na democracia" não é a "questão principal” para Marcuse. Certamente, não defende uma "ditadura educacional pura e simplesmente". Antes de mais nada, trata-se de se constituir dois juízos de valor irredutíveis: “1. É melhor viver do que não viver; 2. É melhor, ter uma boa vida [gutes Leben] do que uma ruim (...). Quando alguém não aceita isso, então não é um debatedor" (MARCUSE in HABERMAS, Philosophishe-politische profile, p. 287). Com efeito, toda a crítica de racionalidade deve levar em conta os aspectos utópicos - deixados de lado pela leitura de Terra - do conteúdo do juízo sobre o bem-viver. Elemento que não se consolida nas formas institucionais em si (seja na ditadura educacional ou mesmo na democracia efetiva do status quo). É a questão do bem-viver que deve anteceder os princípios das instituições e não o contrário. E, nesse sentido, é fundamental compreendermos os destinos da utopia no pensamento marcuseano. Pois ali, a articulação do bem-viver e das instituições se mostram evidentes. Decerto, a ausência deste aspecto - que, aliás, é bem mais articulada em Habermas - torna limitada a crítica de Terra ao pensamento de Marcuse. Talvez, um problema que possamos encontrar na recepção brasileira de Habermas.

11 MARCUSE, Das Ende der Utopia, p. 11.

12 MARCUSE, Das Ende der Utopia, p. 10. 
também a profa. Maria das Graças, considerando assim a concretude utópica em contraste com a facticidade imediata. Consequentemente, dado este contraste, é possível dizer, na linguagem marcuseana, que a utopia tenha uma função crítica. Função que, por sua vez, precisa ser avaliada em sua historicidade.

Todavia, considerando o pensamento crítico como um exercício de reflexão sobre o presente, como se consolida o caráter utópico na contemporaneidade? Pois é nesse sentido que Marcuse inverte a proposição de Marx e Engels, conferindo, então, nova tendência no corpo crítico ao capitalismo pela direção que segue da ciência à utopia. Decerto, essa inversão não deve ser lida como uma "fuga da realidade", como bem pode afirmar certo habermasianismo. Trata-se de compreender o destino da crítica enquanto "fim da utopia", reconhecendo nessa formulação não a "finalidade" teleológica que orienta a tendência social, mas - dialeticamente - enquanto realização efetiva da historicidade das lutas. Nesse sentido, percebemos com Marcuse o paradoxo da utopia na contemporaneidade pelo qual seu "fim" seria a efetivação de seu conteúdo na realidade social. Mais ainda, trata-se de um exercício dialético refinado que exige nossa reflexão sobre a utopia junto à sua descrição fantástica, também em sua historicidade e, nisso, operar o campo utópico como uma reserva crítica da realidade estabelecida.

Para tanto, a história materialista das utopias é fonte indispensável. E aqui, o estudo da profa. Maria das Graças se mostra fundamental. Às portas da Modernidade, compreendemos com sua pesquisa a natureza utópica dos primeiros anos desse período nas figuras clássicas de Morus, Campanella e Bacon. Mas também, um terceiro "M" se faz importante nessas análises: Moses Finley - que, em um artigo em homenagem a Marcuse, ${ }^{13}$ lança uma perspectiva materialista histórica sobre esse material utópico de maneira bastante complementar às investigações de nossa professora homenageada. Assim, o campo histórico pelo qual estes três "Ms" transitam confere à nossa investigação sobre a historicidade da utopia (e seu caráter crítico) um universo amplo que segue da Antiguidade ao período pósRevolução Industrial. Notemos os desdobramentos disso.

\section{$\mathrm{O}$ avesso materialista}

De um modo geral, Finley e Souza bebem da mesma fonte: a historiografia marxista britânica de análise econômica sobre a constituição da classe trabalhadora na aurora da Modernidade. Ambos não dispensam a articulação da estrutura econômica em que incidem as narrativas utópicas. Com efeito, ainda que com variações, concordam com o fato de que a utopia é uma construção narrativa própria à Modernidade. A autora segue a perspectiva de Raymond Trousson, para quem a utopia não tem lugar no mundo medieval ou antigo. Isso porque as imagens do Paraíso bíblico ou da Idade de Ouro da humanidade (descrita por

13 FINLEY, “Utopianism Ancient and Modern” in WOLFF \& MOORE Jr., The Critical spirit: essays in honor of Herbert Marcuse, pp. 3-21. 
Hesíodo) ou mesmo o reino da Cocanha (do século XI) não contém um elemento fundamental das descrições utópicas, a saber: "uma organização social ou política que tenha como fim assegurar o bem-estar dos indivíduos". ${ }^{14}$

Finley, embora conceda certo teor utópico à Antiguidade, ${ }^{15}$ também concorda com a perspectiva da autora. Para ele, as descrições das idades fantásticas remetem muito mais a um tempo mítico do que a um tempo histórico, de modo que, por exemplo, a Idade de Ouro de Hesíodo serve antes como sombra para definir por oposição a verdade da Idade de Ferro, período em que subjazem os males com os quais a humanidade deve conviver e, sobretudo, perecer. Nesse sentido, a Idade de Ouro antes se fixa, na verdade, no tempo mítico, deixando à Idade de Ferro a realidade do tempo histórico. Mesmo com a possibilidade de ressurgir a Idade de Ouro, como pregam movimentos milenaristas, esta virá "por ato de graça e não por uma ação social, e será uma Idade de Ouro somente para eleitos". ${ }^{16}$ Finley conclui, pois, que a marca da diferença dessas narrativas míticas para as narrativas utópicas se deve ao fato de que as primeiras remetem às sociedades "pré-políticas", pelos quais não estão refletidas a "organização social capaz de assegurar o bem-estar dos indivíduos", como afirmava a profa. Maria das Graças. Nos mitos encontram espaço os mártires e heróis; na utopia, o lugar é da política. Isso porque, ao invés da dinâmica mítica em que as narrativas tratam da mudança dos protagonistas da ordem, na utopia interessa a mudança da ordem em que os protagonistas operam. ${ }^{17}$ No campo utópico, não se trata de uma inversão de papéis, mas de uma outra organização com outras funções sociais. As sociedades utópicas são, portanto, políticas na essência.

Na verdade, pensar o político do campo utópico permite compreender a paradoxal historicidade de seu caráter a-histórico. Pelo próprio neologismo de Thomas Morus, Finley compreende que o avesso transcende a articulação entre o fantástico desse não-lugar e a realidade a que se contrapõe. Pois o topos pretendido por Morus, não se reduz apenas ao sentido de negação do "não-lugar". Finley encontra em Morus também o lugar político da "felicidade", do "bem-viver", do prefixo grego "eu", posto que - das palavras de Morus -

14 SOUZA, “O real e seu avesso: as utopias clássicas", p. 13.

$15 \mathrm{O}$ autor leva em consideração certas narrativas de teor utópico nas "fantasias privadas" e nas "práticas mágicas" que floresciam nas camadas populares em resposta às restrições que compunham suas vidas, tal como descrito em alguns versos da Odisseia. V. FINLEY, "Utopianism Ancient and Modern”, p. 8.

16 FINLEY, “Utopianism Ancient and Modern”, p. 7. Com esse mesmo argumento, Finley desconsidera a república platônica como uma utopia, mas sim uma construção de uma sociedade ideal e, portanto, externa às variações históricas. Ou ainda, pensando os movimentos milenaristas, é possível haver uma tendência de retorno à Idade de Ouro, ou ao Paraíso. No entanto, Finley lembra que tais movimentos antes liberaram rituais de martírio e sacrifício ao invés de processos de transformação social, um horizonte fundamental para as intervenções modernas da utopia (FINLEY, “Utopianism Ancient and Modern”, pp. 7-9).

17 Como exemplo dos limites das narrativas míticas antigas, Finley recorda a passagem da comédia Ecclesiazusae de Aristófanes cujos personagens de uma sociedade fantástica questionam por quem irá lavrar a terra na sociedade fantástica e, mantendo a ordem, tem na escravidão a melhor reposta. FINLEY, "Utopianism Ancient and Modern", pp. 14-15. 
o termo correto não é Utopia, mas antes o nome é Eutopia: o lugar da felicidade. ${ }^{18}$ Algo muito próximo à "questão central" para Marcuse: o juízo de valor sobre o bem-viver que é o pressuposto maior das utopias. ${ }^{19}$ Assim, o caráter histórico da utopia evita a aproximação ao idealismo, como um ideal regulador normativo. De outro modo, a ordem histórica da utopia se dá justamente naquilo que a impede de se efetivar na história: sua impraticabilidade, seu impossível - uma vez que, lembra Marcuse, se referem "a projetos para mudanças sociais consideradas impossíveis". ${ }^{20}$ Pois, na marca do impossível está a constituição histórica da utopia. Nesse ponto, a utopia não reproduz a temporalidade circular do mito, mas no caráter impraticável da sua "organização social” emerge a sua forma política e, por conseguinte, a pergunta crítica por excelência: afinal de contas, o que impossibilita efetivar o bem-viver na sociedade estabelecida?

\section{A ruptura com o contínuo, a ruptura com o mito}

A maior precisão dessas elucubrações segue de uma caracterização mais precisa das utopias clássicas. Notemos como a profa. Maria das Graças e Moses Finley recobrem as categorias que estruturam narrativas utópicas a fim de perceber o sentido de sua ruptura com as estratégias míticas.

É notável o "insularismo" destas sociedades, a marca de seu isolamento espacial como sugere a descrição das utopias clássicas. Algo que, segundo a profa. Maria das Graças, possibilita duas interpretações complementares. ${ }^{21}$ Primeiramente, o isolamento configura uma proteção contra as influências nefastas das sociedades realmente existentes. Através desta proteção, esta racionalidade pode ser composta por uma ordem autônoma de governo. Mas também, em segundo, toda a influência externa deve ser expurgada, compreendendo uma nova ordem dos seus elementos sociais. Há uma ruptura com a sociedade que permite notar o sinal invertido da utopia, potencializando ainda mais o isolamento em seu caráter crítico. Em especial, nessa configuração isolada, as utopias efetivam sua racionalidade no interior de uma sociedade de trabalho - em geral coletivista - organizada a tal ponto que o produto maior será o "bem-viver". Seja por uma ordem política (como a Utopia de Morus) ou por uma ordem científica (como a Nova Atlântida de Bacon), é no reconhecimento do trabalho em vistas do "bem-viver" que a realidade utópica se efetiva e não mais, como no reino mítico paradisíaco, no ócio. Aliada do tempo da produção, a utopia rompe com o tempo circular do mito e das estruturas que reproduzem a ordem. Algo que se faz compreender através de Marcuse, quando afirma que as possibilidades utópicas não podem ser pensadas mais a partir da "continuação com o antigo, nem mesmo existindo no mesmo contínuo histórico que o

18 FINLEY, “Utopianism Ancient and Modern”, p. 3.

19 Ver acima nossa nota 9.

20 MARCUSE, Das Ende der Utopia, p. 10.

21 SOUZA, "O real e seu avesso: as utopias clássicas", pp. 13-14. 
delas. Antes, elas pressupõem uma ruptura com o continuum histórico; elas pressupõem a diferença qualitativa entre uma sociedade livre e sociedades que são ainda servis". ${ }^{22}$ Em outras palavras, o isolamento não é o sinal de uma fuga monástica do mundo, mas a composição de uma racionalidade constituída na ruptura com o continuum histórico, com o tempo circular mítico, na mesma medida em que se alia ao caráter produtivo das transformações históricas.

Ora, é nesse caráter histórico que a utopia também se estrutura e se modifica. Finley ressalta as diferenças que as narrativas utópicas apresentam no decorrer da Modernidade, sobretudo a partir da Revolução Industrial, quando afirma:

As utopias antigas ou dos primeiros anos da modernidade foram forçadas a aceitar a escassez de bens como um dado e, portanto, a ressaltar a simplicidade, o limite das vontades, o ascetismo e a sociedade estática. Depois, veio a liberação de novas fontes de energia e, com ela, um fluxo de imaginação utópica tecnológica, desde Condorcet a Fourier, através de Jules Vernes e H. G. Wells. Eles compreenderam que, pela primeira vez na história, seriam criadas as possibilidades técnicas para uma nova espécie de utopia, em que a abundância substitui a escassez, em que as possibilidades humanas teriam um salto adiante para algo impensável anteriormente fora do mundo do mito. ${ }^{23}$

Com efeito, a própria utopia se estrutura historicamente nesse campo de transformações da realidade estabelecida, mobilizando novas fontes para a ordem social. É nesse sentido que Finley diferencia a utopia em dois níveis. Dada a escassez característica na aurora da Modernidade, as utopias clássicas tendem a se configurar como ordens sociais "estáticas" que asseguram o bem-estar no limite de sua produtividade. Com as novas fontes liberadas pela Revolução Industrial, no entanto, a utopia se configura como "dinâmica", organizando em suas narrativas todo um universo das tecnologias - ainda que de um ponto vista crítico.

Decerto, como lembra a profa. Maria das Graças, Thomas Morus organiza sua utopia no avesso das transformações sociais que alteram toda a ordem de relações proprietárias na Inglaterra cada vez mais ocupada pelos carneiros e suas vantagens econômicas para as forças capitalistas em seus primeiros passos de acumulação primitiva. ${ }^{24}$ Diante do cenário da escassez (e da terra devastada pela acumulação capitalista), a própria utopia de Morus expressa em sua ordem social a necessidade de garantir o bem-viver mediante restrições e controles materializados em aparatos conscientemente disciplinares que "desempenhavam não uma função econômica e higiênica, mas moral" em

22 MARCUSE, Das Ende der Utopia, p. 9.

23 FINLEY, "Utopianism Ancient and Modern”, p. 13.

24 SOUZA, “O real e seu avesso...”, pp. 18-19. 
correspondência com certo ascetismo. ${ }^{25}$ Todavia, tal caráter estático da utopia perde sentido diante da realidade pós-industrial.

\section{Marcuse e o fim da utopia}

A narrativa utópica sofre, então, uma segunda ruptura após a Revolução Industrial, como lembra Finley, com a liberação de novas fontes de energia em vistas da produção de uma nova sociedade. ${ }^{26}$ Nesse sentido, o avanço tecnológico altera o lugar social das narrativas utópicas. Movimento a que Marcuse era sensível, quando afirma, já no cenário do capitalismo tardio:

\footnotetext{
Hoje, qualquer forma do mundo concreto, de vida humana, qualquer transformação do ambiente técnico e natural é uma possibilidade, e o lugar desta possibilidade é histórico. Hoje, temos a capacidade de transformar o mundo em um inferno, e estamos nos encaminhando bem nesse sentido. Também temos a capacidade de transformar isso no oposto do inferno. Isto significaria o fim da utopia, isto é, a refutação daquelas ideias e teorias que usam o conceito de utopia para denunciar certas possibilidades históricas. ${ }^{27}$
}

A refutação é possível pois, a cada novo passo dos avanços tecnológicos: o que outrora era impraticável passa a ser uma alternativa viável. Eis o "fim da utopia", a efetivação da mesma em uma nova ordem do tempo: quando o impossível passa a ser existente no horizonte político e social. Movimento que exige do pensamento crítico um esforço de reflexão maior sobre o salto qualitativo que propicia o limiar - por vezes, nada claro - entre o inferno de sociedades servis e as potencialidades das sociedades livres. Refuta-se, pois, o lugar impossível da utopia determinando-o como a possibilidade que temos de mais próxima. E entender os bloqueios, as resistências (e, por que não, repressões?) do status quo contra as "forças centrífugas" contidas nas utopias mostra-se um imperativo para o teórico crítico. $^{28}$

25 FINLEY, “Utopianism Ancient and Modern”, p. 14.

26 No caso, Finley apresenta duas possibilidades. A primeira, conforme a citação acima, das utopias que valorizam o progresso tecnológico e as potencialidades sociais a partir dele. Mas é possível remeter a um segundo grupo, cético quanto aos avanços tecnológicos e de forte influência nos Estados Unidos, como as "propostas alternativas e críticas surgindo da análise e da crítica da sociedade industrial” de Thoureau e William Morris (FINLEY, “Utopianism Ancient and Modern”, p 13).

27 MARCUSE, Das Ende der Utopia, p. XX

28 Lembremos aqui as passagens de $O$ homem unidimensional, em que Marcuse compreende o "verdadeiro inimigo" contra o qual a sociedade industrial avançada se volta: "As capacidades (intelectuais e materiais) da sociedade contemporânea são incomensuravelmente maiores do que jamais foram - o que significa que o escopo da dominação da sociedade sobre o indivíduo é incomensuravelmente maior do que antes. Nossa sociedade se distingue pela conquista das forças sociais centrífugas [centrifugal social forces] mais precisamente 
A leitura acurada dos textos marcuseanos compreendem o equívoco de tratar o "fim da utopia" como uma tecnofobia, como afirmaria Terra. Seguindo a esteira de Lebrun e Habermas, o intérprete acaba por considerar o risco de uma leitura contrária à tecnologia e às ciências a partir das denúncias críticas que Marcuse opera sobre o teor de dominação e da instrumentalização do saber científico e tecnológico. Em nota, o intérprete chega a considerar que a linha marcuseana seria contrária aos avanços das pesquisas sobre organismos geneticamente modificados, uma vez relacionados ao objetivo final na ordem capitalista do lucro, a despeito das descobertas que promovem organismos mais resistentes às pragas e capazes de reduzir o uso de agrotóxicos. Além disso, pensando na estabilidade de certos saberes científicos, Terra compreende como parte do pensamento marcuseano quase como um devaneio sobre os conteúdos científicos, cuja forma "revolucionária" de nova sensibilidade evitasse o racionalismo dominador dos conceitos a despeito de descobertas fundamentais como, por exemplo, a mecânica quântica. ${ }^{29} \mathrm{O}$ intérprete desafia, com Lebrun: “'O que pode ser uma outra mecânica quântica?’ (...) Ficamos esperando a resposta (...)". ${ }^{30}$

Tal interpretação não poderia estar mais equivocada. Mas aceitemos a provocação como um recurso didático. Pois permite esclarecer o quanto a possibilidade de um "fim da utopia" não é o avesso da tecnologia, mas da ordem social em que ela se localiza. Decerto, como aponta Douglas Kellner e Steven Best, não se trata de uma crítica romântica aos avanços tecnológicos e científicos. ${ }^{31}$ A questão central - que certos habermasianos teimam em não ver - não é o conteúdo científico e tecnológico, mas sua disposição social. Afinal, o que significa os grandes avanços genéticos em um sistema corporativo dominado e financiado por uma empresa como a Monsanto - sistema que, aliás, contraria a redução de agrotóxicos como demonstram inúmeras pesquisas de reconhecimento responsável? Mais ainda - e mais grave para nossa pesquisa: o intérprete deixa de lado a questão central está posta em Teoria Tradicional e Teoria Crítica, fundamental para a interpretação do exercício de reflexão em jogo diante da coisificação do saber. Segundo Horkheimer, diante de movimentos científicos da teoria tradicional como a Física da mecânica quântica,

Não há dúvidas de que tal elaboração representa um momento de revolução e desenvolvimento constantes da base material desta sociedade. Na medida

\footnotetext{
pela Tecnologia do que pelo Terror, sobre a dupla base da eficiência esmagadora e de um crescente padrão de vida" (MARCUSE, O homem unidimensional: estudos da ideologia da sociedade industrial avançada, p. 32, com alterações nossas). No fim das contas, as guerras políticas (frias e assassinas) se voltam não entre as partes, mas contra a possibilidade de novas forças centrífugas, afastadas dos polos unidimensionais de oposição e, por isso mesmo, marcas de transformação sobre o status quo.

29 TERRA, "Herbert Marcuse...”, pp. 148-149.

30 TERRA, "Herbert Marcuse...", p. 149, com citações de LEBRUN, "Sobre a tecnofobia” in NOVAES, A. (org.), A crise da razão.

31 V. BEST \& KELLNER, The postmodern adventure...
} 
em que o conceito de teoria é independentizado, como que saindo da essência interna da gnose [Erkenntnis], ou possuindo uma fundamentação ahistórica, ele se transforma em uma categoria coisificada e, por isso, ideológica. ${ }^{32}$

Ora, pensar o desenvolvimento da teoria genética ou mesmo da mais elementar mecânica quântica não é, pois, um problema para Marcuse e sua geração. No entanto, pensálos de maneira independentizada - como, aliás, acaba transparecendo a defesa de Terra pelas pesquisas de organismos geneticamente modificados - é, de fato, o risco bem presente para uma perspectiva que não deixa de ver os problemas dos avanços da química utilizados nas câmaras de gás ou dos avanços da biologia em termos de controle de mercadoria e da economia da subsistência.

Pois bem, a noção marcuseana de "fim da utopia" em nada corresponde à tecnofobia e outros medos. De outro modo, a utopia "dinâmica" é antes, como já aponta Finley, baseada no potencial libertador das tecnologias e das ciências. Para Marcuse, colocar essa possibilidade nos termos de utopia em vias de efetivação significa não apenas uma diferença quantitativa de maior produtividade. No horizonte, nosso autor vislumbra um "salto qualitativo" que atinge a ordem social como um todo. Para Marcuse, a utopia "dinâmica" de Finley pode muito bem ser interpretada como a passagem dialética possível em que o reino da necessidade não é mais a oposição ao reino da liberdade (o que estrutura em grande medida o campo da escassez das utopias estáticas, como em Morus). Com as novas fontes da tecnologia pós-revolucionária, trata-se de compreender o reino da necessidade junto ao reino da liberdade.

Tal passagem fica mais nítida na conferência "The realm of freedom and the realm of necessity - a reconsideration" (1969), quando Marcuse trata de maneira mais direta a questão das novas relações entre liberdade e necessidade no desenvolvimento tecnológico do capitalismo tardio. Na ocasião, Marcuse descreve como os dois domínios da liberdade e da necessidade, outrora antagônicos, ${ }^{33}$ têm suas fronteiras diluídas com o desdobramento tecnológico das sociedades industriais avançadas. Isso porque considera as mudanças nos processos de produção que, cada vez mais integram o trabalho intelectual, como a presença determinante de setores de engenharia e supervisão na organização racional (e, até, administrada) do trabalho.

32 HORKHEIMER, "Teoria tradicional e teoria crítica" in BENJAMIN et al., Textos escolbidos, p. 129.

$33 \mathrm{E}$ até mesmo inescapavelmente antagônicos, mesmo para a constituição de uma sociedade sem classes, como descrito em muitos textos de Marx, sobretudo aqueles em defesa do progresso das forças produtivas, elogiosas até mesmo de modelos tayloristas de produção. V. MARCUSE, "The realm of freedom and the realm of necessity - a reconsideration", pp. 22-23. 
Não se trata de um elogio "romântico" de Marcuse ao tempo livre do trabalho, ${ }^{34}$ mas de um exercício fino de reflexão sobre as contradições em jogo, reformuladas no tabuleiro do capitalismo tardio. Pois, com a diluição das fronteiras entre a necessidade e a liberdade na também chamada sociedade da afluência, um domínio se justapõe ao outro. Movimento que implica em duas possibilidades. Por um lado, o reino da necessidade avança sobre o reino da liberdade com a oferta de novos aparatos que codificam os signos do homem livre sob a condição da circulação de mercadorias, no espetacular mundo do consumo. Por outro, é possível que o reino da liberdade avance sobre o campo das necessidades, com a produtividade reconhecidamente capaz de conferir um salto qualitativo dos padrões de vida. Daí, a conclusão:

Estas duas tendências, uma que estende o reino da necessidade ao reino da liberdade, a outra, a possível extensão do reino da liberdade para o reino da necessidade, expressam as contradições básicas do capitalismo em um estágio de progresso técnico competitivo: de um lado, o conflito entre o padrão crescente de vida por extensão da forma mercadoria dos homens e das coisas (...) e, de outro, o crescente potencial de liberdade no interior do reino da necessidade, a saber, a possível transformação do reino da necessidade pelos homens e pelas mulheres na determinação de suas próprias necessidades, de seus próprios valores e de suas próprias aspirações..$^{35}$

Ora, o campo utópico se abre nesse segundo momento e tal afirmação, muitas vezes considerada ingênua pelos intérpretes, procura recolher a verdade da afirmação utópica contemporânea de Marcuse: "Soyons realistes, demandons l'impossible?" Afinal, o que seria esse impossível a ser requisitado?

\footnotetext{
34 Curiosamente, ao descrever os momentos em que Marx pensaria diversamente o reino do trabalho como um momento externo ao domínio da necessidade (alienante), Marcuse recusa como fundo de sua crítica a imagem famosa do trabalhador livre para caçar, pescar e fazer crítica literária, presente nos Manuscritos Econômico-Filosóficos; pois, por mais que este trabalhador fosse múltiplo em suas funções, nada dessa pluriatividade garante o fim da divisão social do trabalho e seu consequente regime de propriedades. De outro modo, para Marcuse, exemplar vem a ser as poucas linhas dos Grundrisse a respeito do automatismo das indústrias e a organização racional das necessidades - um cenário bastante próximo da realidade das sociedades industriais avançadas (MARCUSE, “The realm of freedom...”, p. 22). Seria nesse estágio que as fronteiras entre os domínios da liberdade e da necessidade passa a ser diluídas, abrindo o compasso para um novo regime de contradições, como veremos a seguir.

35 MARCUSE, “The realm of freedom...”, p. 24.
} 


\section{Do impossível como político}

A pergunta nos leva a uma última consideração sobre o caráter político e crítico da utopia. Afinal de contas, se a realização da liberdade no reino da necessidade é uma realidade possível, o que resta do impossível a ser demandado? Pergunta que coloca em xeque a possibilidade de criticar a própria realidade estabelecida, cujo domínio técnico permite materialmente efetivar os desejos do reino da liberdade. No entanto, Marcuse é atento para os desígnios dessa Realpolitik. O impossível não é uma mera questão de tempo a ser realizado, mas um imperativo a ser absorvido por uma nova racionalidade política.

Exigir o impossível é o avesso da esfera fechada da sociedade unidimensional. Nela, as contradições se estruturam de tal maneira que o sistema de oposições passa a ser integrado. De uma maneira mais imediata, é inegável que na sociedade industrial avançada o reino de liberdade esteja mais articulado, que os trabalhadores sejam reconhecidos, no limite, como sujeitos de direito. $\mathrm{Na}$ verdade, como Marcuse afirma em seu Prefácio político (1966), não "faz mais sentido falar sobre a libertação de homens livres (...) quando homens e mulheres gozam de mais liberdade sexual [mas não só] do que antes." ${ }^{36}$ Neste cenário, fazer a crítica da sociedade nesses termos não é suficiente, se é que faz algum sentido.

Contudo, Marcuse reconhece neste cenário a lógica das novas liberdades reduzidas às fronteiras do domínio da necessidade. É por isso que não apenas se estabelece um sistema de oposições integradas (diluindo e contendo as manifestações explosivas das contradições sociais), mas também explicita a verdade das novas liberdades reduzidas à necessidade dos tempos: a de que "esta liberdade e a satisfação estão transformando a vida na terra em um inferno". ${ }^{37} \mathrm{O}$ realismo utópico está em considerar o inferno como a verdade que ilumina o todo, base crítica contra a Realpolitik que organiza este estágio social, em que é "fácil e sensível ver" nestes infernos "somente bolsões de pobreza e miséria dentro de uma sociedade em desenvolvimento capaz de eliminá-los gradualmente e sem uma catástrofe." No entanto, complementa Marcuse, embora esta seja uma interpretação "realista e até mesmo correta", fica a questão: "eliminadas a que preço? - não em dólares e centavos, mas em vidas humanas e liberdade humana?"38

Contrário ao realismo da Realpolitike, Marcuse reforça o realismo da utopia: a demanda pelo impossível tornado viável pelas condições materiais vigentes. Colocar o impossível como princípio político é andar no avesso das demandas possíveis; é indicar o lugar onde a sociedade apenas tocou, mas cuja racionalidade instituída impede qualquer

36 MARCUSE, Eros and civilization: a philosophical inquiry into Freud, p. XIII [colchetes nossos]. Consideramos também os novos direitos sociais que as sociedades industriais avançadas operam no Welfare State, conforme O Homem Unidimensional.

37 MARCUSE, Eros and civilization..., p. XIII.

38 MARCUSE, Eros and civilization..., p. XIII. 
avanço, quando não o reprime. Nesse ponto, a utopia se torna uma chave crítica valiosa, uma vez que

há um único critério válido para a realização possível, a saber, quando as forças material e intelectual estão tecnicamente à mão embora sua aplicação racional seja evitada pela organização existente de forças de produção. ${ }^{39}$

A utopia revela aqui seu caráter crítico: a demanda pelo impossível não é exigir o que não se pode, mas a demanda por uma outra racionalidade pela qual o impossível não seja apenas o impraticável, mas o horizonte emancipável das realizações humanas.

\section{UTOPIA: ON IMPOSSIBLE AS POLITICAL QUESTION}

Abstract: This paper constitutes an analysis on historical contents of utopia. In this sense, it articulates reflections by Souza and Finley on classical utopias as well as develops the contemporaneity of this concept by Marcuse's perspective on "end of utopia". At the end, the paper intends to understand utopical thinking as a critical thinking on Modernity.

Keywords: Utopia - Historicity - Critical Theory - Modernity

\section{REFERÊNCIAS BIBLIOGRÁFICAS}

BACON, Francis. A nova Atlântida. São Paulo, Abril Cultural, I973.

BEST, Steven \& KELLNER, Douglas. The postmodern advernture: science, technology, and cultural studies at the Third Millenium, New York, London: The Guilford Press, 2001.

DUBIEL, Helmut, Kritik und Utopie im Werk von Herbert Marcuse, Frankfurt am Main: Suhrkamp, 1992.

HABERMAS, Jürgen. "Einleitung zu einer Antifestschrift (1968)" in HABERMAS, J.. Philosophisch-politische Profile, Frankfurt am Main: Surkhamp Verlag, 1984.

Discurso filosófico da modernidade: doz̧e lições, trad. Luiz S. Repa e Rodnei Nascimento, São Paulo: Ed. Martins Fontes, 2000.

HORKHEIMER, Max. "Teoria tradicional e teoria crítica" in BENJAMIN et al. Textos escolhidos, São Paulo, Abril Cultural, 1973.

39 MARCUSE, Das Ende der Utopia, p. XXXXX 
FINLEY, Moses I.. "Utopianism Ancient and Modern" in WOLFF, Kurt H. \& MOORE Jr., Barrington, The Critical spirit: essays in honor of Herbert Marcuse, Boston: Beacon Press, 1967, pp. 3-20.

FOUCAULT, Michel. "O que são as luzes?” in FOUCAULT, Arte, Epistemologia, Filosofia e História da Medicina (Ditos e escritos - vol. VII), trad. Vera L. A. Ribeiro, Rio de Janeiro: Forense Universitária, 2011.

MARCUSE, Herbert. Eros and Civilization - A Philosophical Inquiry into Freud, Boston: Beacon Press, 1966.

. Das Ende der Utopie, Berlin: Verlag Peter von Maikowski, 1967.

. "The Realm of Freedom and the Realm of Necessity: A Reconsideration", Praxis, 5, no. 1(1969), pp. 20-25.

. O homem unidimensional: estudos da ideologia da sociedade avançada, trad. Robespierre de Oliveira et al., São Paulo: EDIPRO, 2015.

MORE, Thomas. A Utopia, trad. Luís de Andrade, Col. Os pensadores, São Paulo, Abril Cultural, 1972.

SOUZA, Maria das Graças de. "O real e seu avesso: as utopias clássicas" in Revista SextaFeira, vol. 6, São Paulo: Ed. 34, s/d, pp. 11-22.

TERRA, Ricardo R. "Herbert Marcuse -Os Limites do Paradigma da Revolução: Ciência, Técnica e Movimentos Sociais" in NOBRE, M. (org.). Curso Livre de Teoria Crítica, Campinas: Papirus, 2008. 